\title{
Metabolic Reprogramming and Cell Adhesion in Acute Leukemia Adaptation to the CNS Niche
}

\author{
Nitesh D. Sharma ${ }^{1,2}$, Esra'a Keewan ${ }^{1,2}$ and Ksenia Matlawska-Wasowska ${ }^{1,2 *}$ \\ ${ }^{1}$ Department of Pediatrics, Division of Hematology-Oncology, University of New Mexico Health Sciences Center, Albuquerque, \\ NM, United States, ${ }^{2}$ Comprehensive Cancer Center, University of New Mexico, Albuquerque, NM, United States
}

Involvement of the Central Nervous System (CNS) in acute leukemia confers poor prognosis and lower overall survival. Existing CNS-directed therapies are associated with a significant risk of short- or long-term toxicities. Leukemic cells can metabolically adapt and survive in the microenvironment of the CNS. The supporting role of the CNS microenvironment in leukemia progression and dissemination has not received sufficient

\section{OPEN ACCESS}

Edited by:

Tanja Nicole Hartmann,

University of Freiburg Medical Center,

Germany

Reviewed by:

Félix A. Urra,

University of Chile, Chile

Vladimir Lj Lazarevic,

Skåne University Hospital, Sweden Juan Manuel Mejia Arangure, Universidad Nacional Autónoma de México, Mexico

*Correspondence:

Ksenia Matlawska-Wasowska kmatlawska-wasowska@ salud.unm.edu

Specialty section:

This article was submitted to

Cell Adhesion and Migration,

a section of the journal

Frontiers in Cell and Developmental

Biology

Received: 30 August 2021 Accepted: 29 November 2021

Published: 10 December 2021

Citation:

Sharma ND, Keewan E and Matlawska-Wasowska K (2021)

Metabolic Reprogramming and Cell

Adhesion in Acute Leukemia

Adaptation to the CNS Niche.

Front. Cell Dev. Biol. 9:767510.

doi: 10.3389/fcell.2021.767510 attention. Understanding the mechanism by which leukemic cells survive in the nutrientpoor and oxygen-deprived CNS microenvironment will lead to the development of more specific and less toxic therapies. Here, we review the current literature regarding the roles of metabolic reprogramming in leukemic cell adhesion and survival in the CNS.

Keywords: central nervous system, CNS, meninges, cell adhesion, metabolism, acute lymphoblastic leukemia, acute myeloid leukemia

\section{INTRODUCTION}

Acute leukemia is characterized by neoplastic proliferation of immature white blood cells, also called blasts, in the bone marrow (BM), which later rapidly disseminate to the blood and other tissues (Colmone et al., 2008; Vardiman et al., 2009; Glait-Santar et al., 2015). Based on the lineage of affected white blood cells, acute leukemia is classified into acute myeloid leukemia (AML) and acute lymphoblastic leukemia (ALL) (Marks et al., 2009; Lyengar and Shimanovsky, 2021). AML is more common in adults and accounts for about $80 \%$ of all AML cases. ALL predominantly occurs in children; it comprises about $80 \%$ of childhood and $20 \%$ of adult ALLs (Lyengar and Shimanovsky, 2021).

Conventional chemotherapy has successfully decreased the mortality rate of patients with acute leukemia (Marks et al., 2009; Rowe and Tallman, 2010; Rubnitz, 2017). However, patients still suffer from refractory disease or relapse, signifying the need for the development of more effective therapies (Hunger et al., 2012; Winter et al., 2018). One of the devastating features of leukemia is the ability of leukemic cells to colonize at secondary sites for tumorigenesis (Valastyan and Weinberg, 2011). Particularly, infiltration of the central nervous system (CNS) by leukemic cells contributes to an increase in leukemia mortality and treatment failure (Basu et al., 2014; Si et al., 2018).

Growing evidence suggests the crucial role of intrinsic and extrinsic factors in modulating leukemic cell survival (Silva et al., 2011; Giambra et al., 2015; Pitt et al., 2015; Moharram et al., 2017; Ribeiro et al., 2018; van der Zwet et al., 2021). Leukemic cells remain in a quiescent state and highly depend on intrinsic survival factors while circulating in the blood (Guan et al., 2003). When leukemic cells enter the homing tissue, the microenvironmental niche provides multiple signaling ques supporting leukemia survival (Ninomiya et al., 2007). Metabolic reprogramming provides cancer cells with a unique flexibility in adapting to a variety of cell-extrinsic and -intrinsic stimuli. These 
metabolic adaptations govern tumor transformation, proliferation, invasiveness, and resistance to therapy (Hanahan and Weinberg, 2011; DeBerardinis and Chandel, 2016). Otto Warburg was the first to recognize the aberrant metabolic behavior of tumor cells. He postulated that cancer tissues have higher levels of glucose uptake compared to normal tissues and that cancer cells rely primarily on aerobic glycolysis to produce adenosine triphosphate (ATP) (Warburg, 1925; Warburg, 1956a). Understanding the mechanism underlying metabolic reprogramming of cancer cells could provide a venue for defining novel therapeutic targets (Wolpaw and Dang, 2018).

Acute leukemias commonly display an increase in glucose uptake and aerobic glycolysis (Suganuma et al., 2010; Kishton et al., 2016; Matthijssens et al., 2021). In addition, enhanced mitochondrial respiration (OXPHOS) increases the reactive oxygen species (ROS) levels in leukemic cells (Han et al., 2019). However, leukemic cells can compensate for the harmful effects of elevated ROS levels by enhancing the expression of antioxidants, which ultimately restore redox homeostasis (Sabharwal and Schumacker, 2014; Khan et al., 2016). Importantly, under energy crisis conditions, leukemic cells rely on non-glycolytic resources (Lee et al., 2013) such as fatty acid oxidation, amino acid oxidation (e.g., methionine, cysteine), and glutaminolysis, which all provide essential intermediates to maintain the Krebs cycle (Tabe et al., 2020). In line, growing evidence suggests that major oncogenic drivers, such as PI3K/Akt/mTOR pathway, MYC, FLT3, and RAS, contribute to metabolic rewiring in leukemic cells (Herranz et al., 2015; Rashkovan and Ferrando, 2019).

Cell adhesion plays a key role in cancer progression and metastasis. Adhesion molecules regulate cancer cell survival, differentiation, proliferation, inflammation, and migration. Alterations in cell-cell and cell-matrix adhesion allow malignant cells to increase their motility and degrade the cellextracellular matrix (ECM) to enter the blood circulation, followed by dissemination to distant sites (Martin et al., 2013). During this multi-step process, cancer cells induce metabolic rewiring to meet distinct metabolic demands (Nepstad et al., 2018; Wei et al., 2020). Recent studies demonstrated that cancer cell adhesion may either induce or be induced by cell signaling pathways associated with metabolic reprogramming (Sousa et al., 2019). In line, several adhesion molecules were identified as critical regulators of leukemia development and chemoresistance (Jacamo et al., 2014; Fonseca et al., 2018; Scharff et al., 2020a; Gutjahr et al., 2021).

The impact of specific genetic lesions (e.g., $M L L$ rearrangements, BCR-ABL), CNS niche, chemokines, cytokines, and growth factors in driving leukemic cells to the CNS and meninges has been extensively reviewed in (Heidari et al., 2016; Gossai and Gordon, 2017; Piovan et al., 2018; Zhou et al., 2019; Lenk et al., 2020; Whiteley et al., 2021). The roles of metabolic reprogramming and cell adhesion in leukemia development and progression have also been discussed elsewhere (Heath et al., 2019; Rashkovan and Ferrando, 2019; Windisch et al., 2019; Härzschel et al., 2020; Scharff et al., 2020a; Di Martino et al., 2021). However, how metabolic reprograming and cell adhesion regulate leukemic cell infiltration to the CNS remains unclear. In this mini review we focus on recent advances toward our understanding of the roles played by metabolic reprogramming and cell adhesion in acute leukemia (ALL, AML) colonization into the CNS.

\section{CLINICAL OVERVIEW OF CENTRAL NERVOUS SYSTEM INVOLVEMENT IN ACUTE LEUKEMIA}

The CNS is a common extramedullary site for infiltrating ALL cells (Lazarus et al., 2006). CNS involvement is detected either at initial treatment or at relapse. The incidence of CNS in ALL at diagnosis is approximately $5-10 \%$. For ALL patients who have received prophylactic CNS directed chemotherapy, the recurrence of CNS disease is 7-15\% (Alakel et al., 2017; Holland et al., 2003; Pinkel and Woo, 1994; Gökbuget and Hoelzer, 1998). Factors associated with CNS-ALL include high white blood cell (WBC) count, hypercellular marrow, and extramedullary infiltration (BLEYER, 1984; Cassileth et al., 1988; Pinkel and Woo, 1994; Cortes, 2001).

CNS infiltration in AML is relatively rare (Galati et al., 2013; Loeb et al., 2016). Approximately $0.6-5 \%$ of AML patients present with CNS disease at diagnosis, and 3-15\% with CNS relapse (Kouser and Hashmi, 2007; Galati et al., 2013; Alakel et al., 2017). Risk factors involved in AML-CNS include elevated serum lactate dehydrogenase (LDH) levels, increased WBC count, subtypes of myelomonocytic/monoblastic/monocytic leukemias, inversion of chromosome 16, mutations in FLT3 and NPM1, expression of CD56 and 11q23 rearrangements (Holmes et al., 1985; Thompson et al., 1986; Chang et al., 2004; Cheng et al., 2015; Rozovski et al., 2015).

While cytospin-based evaluation of cerebrospinal fluid (CSF) is used for diagnosis of CNS disease/relapse in leukemia (Del Principe et al., 2014), this diagnostic method does not identify patients who have occult CNS involvement (Martínez-Laperche et al., 2013; Bartram et al., 2018; Del Principe et al., 2021). Furthermore, studies showed that CNS prophylaxis (cranial radiation and intrathecal chemotherapy) is associated with various neurological toxicities (Pochedly, 1977). Thus, it is imperative to understand the mechanism underlying CNS involvement to develop more accurate diagnostic tools and novel therapies that will eradicate leukemic cells from the CNS while causing less adverse neurotoxicity.

\section{METABOLIC REPROGRAMMING OF ACUTE LEUKEMIA IN THE CENTRAL NERVOUS SYSTEM}

The CNS serves as a sanctuary site, in which leukemic cells evade the immune response and systemic chemotherapy (FrishmanLevy and Izraeli, 2017). Metabolic adaptation in the CNS niche is a prerequisite for the long-term survival of leukemic cells and the recurrence of the disease (Savino et al., 2020). Leukemic cells depend on cellular metabolism rewiring to survive in nutrientpoor and hypoxic microenvironments (Cairns et al., 2011; Cha 


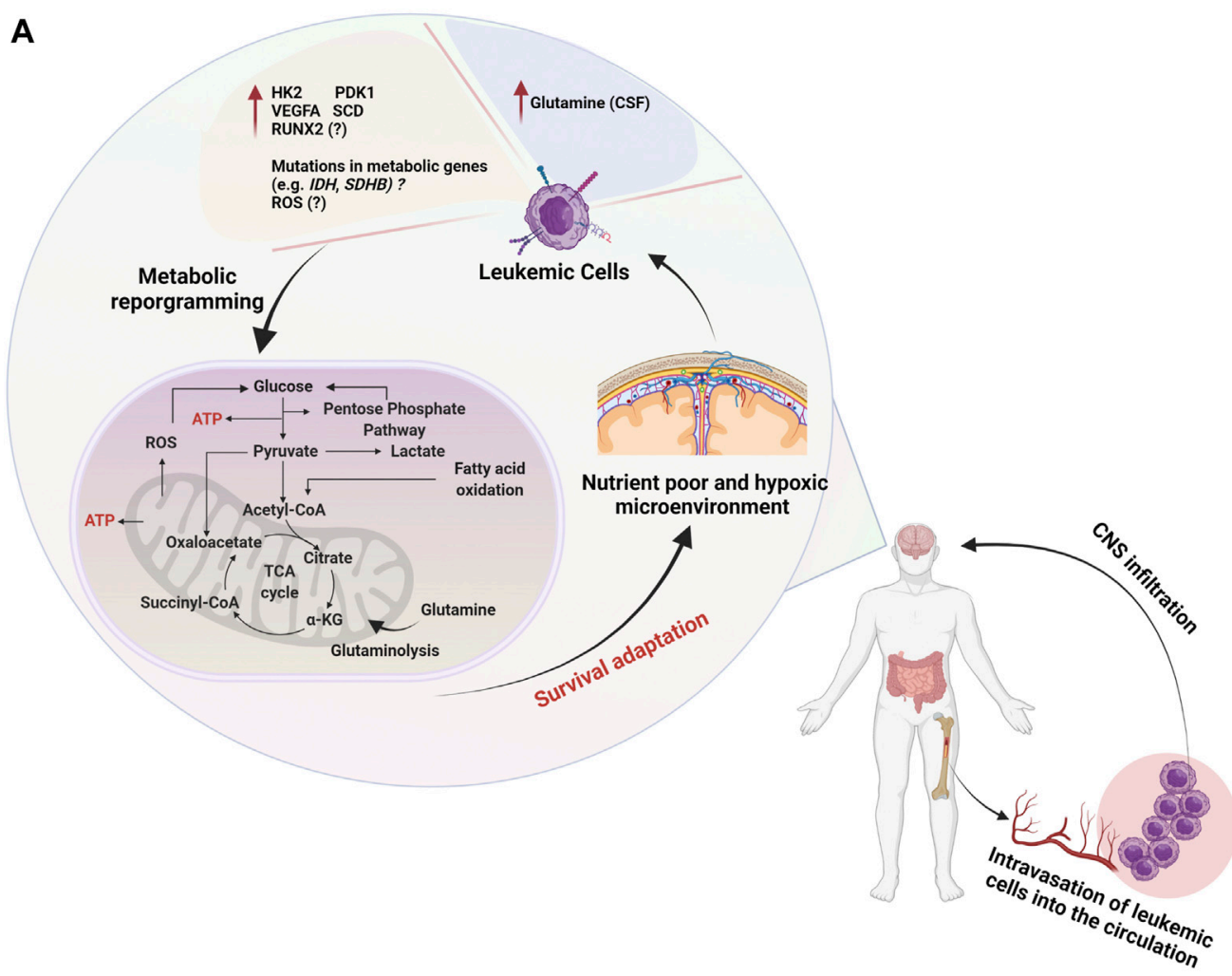

B

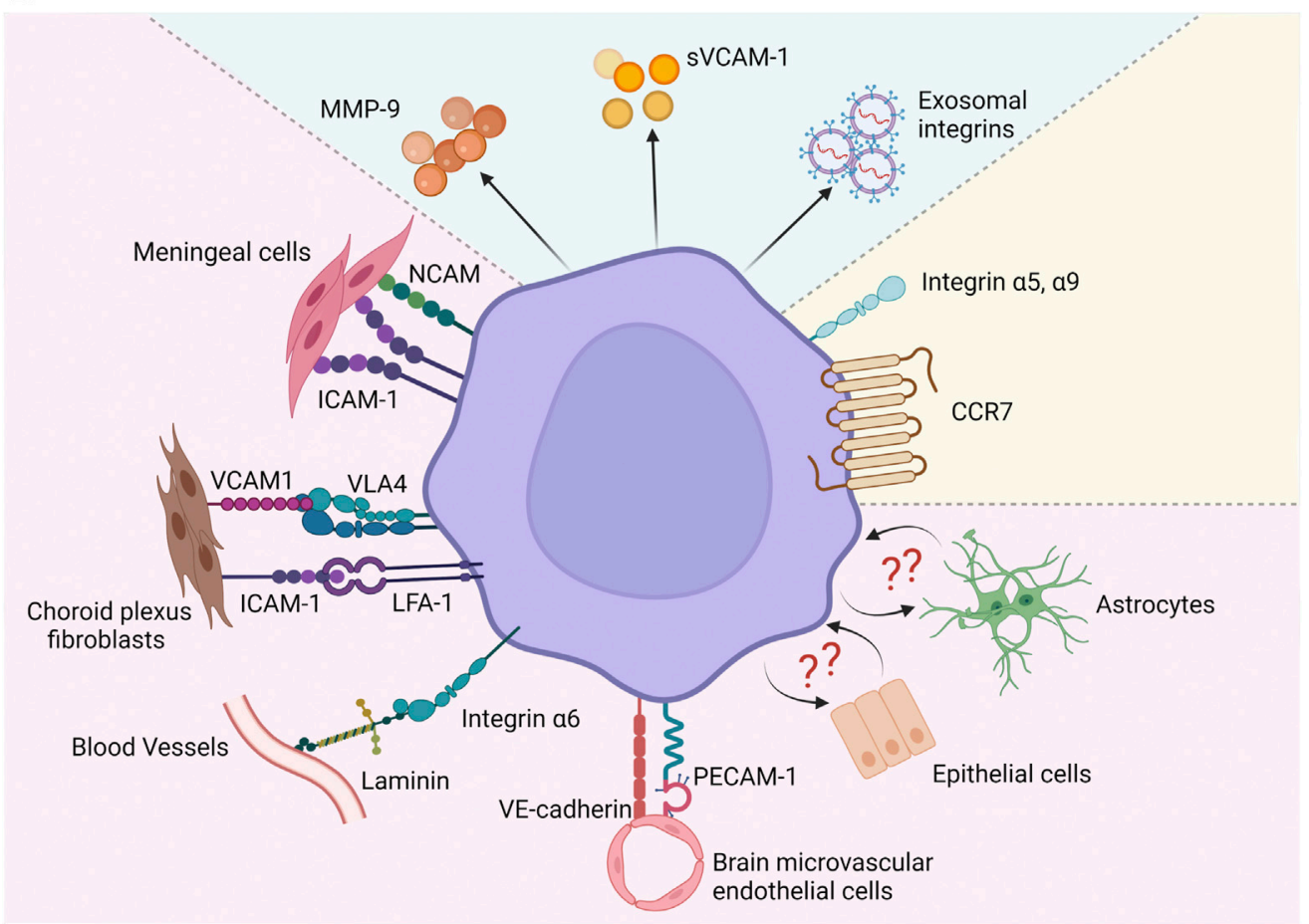

FIGURE 1 | A schematic illustration of metabolic reprogramming and adhesion pathways involved in the central nervous system (CNS) niche in acute leukemia. (A) Leukemic cells can adapt to nutrient-poor and oxygen-deprived CNS by modulating the expression of metabolic and hypoxia-associated genes. (B) Upregulation of adhesion molecules may facilitate leukemic cell infiltration and survival in the CNS microenvironment. 
and Lee, 2016; DeBerardinis and Chandel, 2016). Thus, metabolic vulnerabilities of leukemic cells could be used for therapeutic purposes (Kuntz et al., 2017; Nachmias and Schimmer, 2018). Despite recent advances in cancer metabolism research, little is known about whether and how cell metabolism affects the migration and adhesion of leukemic cells in the CNS. A better understanding of these metabolic adaptations will advance the development of novel treatment strategies. Below, we discuss major metabolic pathways and their roles in leukemia colonization of the CNS (Figure 1A).

\section{Glycolysis}

Glycolysis takes place within a cell's cytosol fraction in the presence (aerobic) or absence (anaerobic) of oxygen. Under anaerobic conditions, lactate is the final product of glycolysis, in which two adenosine triphosphates (ATP) are formed. In aerobic conditions, a glucose molecule is transformed into two pyruvate molecules, which are processed into lactate or enter into the Krebs cycle. This process generates 4 ATP and 2 nicotinamide adenine dinucleotide hydrogen (NADH) molecules (Allard et al., 1994).

Strong evidence suggests that leukemic cells have increased glycolysis (Warburg, 1956b; Boag et al., 2006; Herst et al., 2011; Calviño et al., 2014; Liu et al., 2014; Poulain et al., 2017; Robinson et al., 2020; Matthijssens et al., 2021). In line with this, Kato et al. (2017) compared the transcriptome of B-cell acute lymphoblastic leukemia (B-ALL) cells derived from the CNS and BM of xenografted mice, and the BM and CSF of pediatric B-ALL patients with CNS disease. CNS-derived leukemic cells adapted to hypoxic conditions by upregulating the genes associated with hypoxia such as hexokinase-2 (HK2), pyruvate dehydrogenase kinase 1 (PDK1), and vascular endothelial growth factor A (VEGFA) whereas genes associated with the cell cycle and oxidative phosphorylation were downregulated (Kato et al., 2017). Interestingly, VEGF mediated B-ALL cell entry and infiltration into the leptomeninges. However, the potential link between VEGF and glycolysis in leukemic infiltration of the meninges has not yet been established.

We recently reported that Runt-related transcription factor 2 (RUNX2) was upregulated in children, adolescents, and young adults with high-risk T-ALL and its increased expression was associated with leukemic cell migration and dissemination of T-ALL to extramedullary sites including the meninges (Matthijssens et al., 2021). RUNX2 potentiated T-ALL metabolic activity by enhancing ATP production and glycolysis in vitro. Specifically, RUNX2 induced LDHA, PGK1, and GLUT1 expression concomitant with an increase in glucose uptake and glycolysis. Treatment with 2DG, an inhibitor of glucose metabolism (hexokinase inhibitor), reduced T-ALL migration, indicating a potential role of glycolysis in RUNX2-mediated T-ALL cell chemotaxis (Matthijssens et al., 2021). Further studies are required to determine whether and how glycolysis affects the ability of leukemic cells to invade and survive in the CNS.

\section{Pentose Phosphate Pathway}

The Pentose Phosphate Pathway (PPP) is an alternative branch of glycolysis. It links glycolysis with the production of ribose and
NADPH. The PPP comprises the oxidative and nonoxidative phases. In cancer cells, the oxidative phase is involved in maintaining the redox balance in rapidly proliferating cells (Xu et al., 2009). The non-oxidative phase allows different glycolytic intermediates to enter PPP. Studies showed that cancer cells modify PPP for survival and proliferation (Stincone et al., 2015; Bhanot et al., 2017). PPP generates pentose phosphate and NADPH, which are vital for lipid synthesis and cell survival under stress conditions (Riganti et al., 2012; Zhang et al., 2014; Lucarelli et al., 2015; Stincone et al., 2015). However, the role of PPP in leukemia infiltration to the CNS has not been elucidated thus far.

\section{Krebs Cycle and Amino Acid Metabolism}

The Krebs cycle, also known as the citric acid or tricarboxylic acid (TCA) cycle is a central pathway for sugar, lipid, and amino acid metabolism. The Krebs cycle produces building blocks in macromolecular synthesis together with the energy and electron acceptors that are used in downstream cellular processes such as electron transport chain (ETC) reactions. The aberrant function of the TCA cycle has been seen in a wide array of diseases (Jacque et al., 2015; Anderson et al., 2018). Succinate dehydrogenase (SDH) is the enzymatic complex responsible for oxidizing succinate into fumarate. Interestingly, recurring mutations in the $S D H B$ gene were identified in T-ALL cell lines and primary pediatric T-ALL samples. These mutations were associated with increased survival of T-ALL cells under hypoxia (Baysal, 2007). In the TCA cycle, isocitrate dehydrogenase (IDH) (Chaturvedi et al., 2013) catalyzes the reversible conversion of isocitrate to alphaketoglutarate $(\alpha-\mathrm{KG})$ (Haselbeck and McAlister-Henn, 1993). Mutations in IDH resulting in a neomorphic enzyme that converts $\alpha$-KG to the oncometabolite R-2-hydroxyglutarate (R2-HG) were found in $20 \%$ of adults AML (Figueroa et al., 2010; Ward et al., 2010; Chou et al., 2011; Fathi et al., 2012; Chaturvedi et al., 2013). The aberrant accumulation of R-2-HG was shown to promote leukemia development (Chaturvedi et al., 2013). While studies on the roles of $S D H B$ and $I D H$ mutations in CNS leukemia are still lacking, it seems plausible to speculate that mutations in metabolic genes may contribute to leukemic adaptation to the CNS niche.

Our group reported upregulation of RUNX2 in primary T-ALL harboring KMT2A-rearrangements and immature/ETP phenotype. RUNX2 increased both, glycolytic and oxidative metabolism as well as the expression of critical regulators of mitochondrial dynamics and biogenesis in T-ALL cell lines (Matthijssens et al., 2021). Upregulation of RUNX2 increased metabolic potential of T-ALL cells and accelerated T-ALL progression and dissemination to the meninges as well as other organs. The role of the TCA cycle in mediating CNS colonization by leukemic cells has yet to be determined.

Amino acid metabolism is involved in protein and nonprotein biosynthesis. Abnormalities in amino acid metabolism have been reported in a variety of cancers, including leukemia (Matre et al., 2016; Musharraf et al., 2017; Raffel et al., 2017; Jones et al., 2018; More et al., 2018; Gregory et al., 2019). Interestingly, children with ALL and associated CNS disease had higher levels 
of glutamine in CSF relative to patients without CNS involvement. Thus, high levels of glutamine were proposed as indicative of CNS leukemia (Peng et al., 2005). Further investigation is required to determine the roles of amino acid metabolism in leukemic colonization of the CNS.

\section{Reactive Oxygen Species}

The organelles involved in the production of ROS are mitochondria (through electron transport), peroxisomes ( $\beta$-oxidation of fatty acids), and the endoplasmic reticulum (via oxidation of proteins). ROS levels were elevated in both chronic (Ciarcia et al., 2010) and acute leukemias (Battisti et al., 2008; Sallmyr et al., 2008). Elevated ROS levels potentiated glucose uptake and proliferation of AML cells (Hole et al., 2013; Robinson et al., 2021). Leukemic cells extracted from the CSF of ALL-bearing mice showed decreased proliferation and viability due to elevated ROS. Interestingly, co-culture of ALL cells with meningeal cells led to a decrease in ROS production concomitant with increased leukemic cell survival and chemoresistance (Basile et al., 2020). Further studies are warranted to determine whether modulating ROS levels could be exploited therapeutically in targeting CNS involved leukemia.

\section{Fatty Acid Metabolism}

Fatty acid synthesis (FAS) occurs in the cytosol, where acetylCoA carboxylase 1 (ACC1) catalyzes acetyl-CoA to malonylCoA, which is further used by fatty acid synthase for fatty acid synthesis (FAS). By mitochondrial $\beta$-oxidation processes, fatty acids are broken down into acetyl-CoA, which then enters the citric acid cycle to produce ATP. Fatty acids can also be converted into triacylglycerol, phospholipids or cholesterol esters. Growing evidence suggests the importance of fatty acid metabolism in leukemia development and survival (Ito et al., 2021). For instance, Tucci et al. (2021) reported a unique interaction between ALL cells and adipocytes. In the presence of leukemic cells, adipocytes transferred free fatty acids to ALL cells to fuel leukemic cell metabolism and alleviate ALL dependence from de novo lipogenesis (Tucci et al., 2021). In line with this, metabolic adaptation was observed in B-ALL cells infiltrating the liver. In response to the hepatic microenvironment, leukemic cells upregulated endothelial lipase, LIPG, which in turn promoted leukemic cell proliferation and survival through the regulation of polyunsaturated fatty-acid metabolism. Furthermore, tissue damage caused by infiltrating leukemic cells induced the release of liver-derived enzymes, which affected stability of chemotherapy drugs and exerted a chemoprotective effect on leukemic cells. (Ye et al., 2021). On the contrary, CSF is poor in fatty acids compared to the plasma. Thus, leukemic cells colonizing the CNS must rely on de novo fatty acid synthesis. Interestingly, B-ALL cells derived from CSF of pediatric B-ALL patients with isolated CNS relapse showed increased expression of stearoyl-CoA desaturase (SCD) compared to diagnostic BM samples (van der Velden et al., 2016; Savino et al., 2020). SCD is a central lipogenic enzyme regulating the synthesis of monounsaturated fatty acids. Furthermore, SCD was also upregulated in CNS ALL cells of animals xenografted with primary B-ALL cells and B-ALL cell lines compared to leukemic cells extracted from the $\mathrm{BM}$ or spleen. The mice injected with SCD overexpressing cells showed enhanced CNS infiltration relative to control animals pointing to the role of SCD-mediated lipid metabolism in facilitating leukemia adaptation to the CNS niche. (Savino et al., 2020). In addition, patients who presented with isolated CNS relapse had increased expression of SCD in a sub-population of BM-derived B-ALL cells at diagnosis (van der Velden et al., 2016).

\section{CELL ADHESION IN LEUKEMIC CELL COLONIZATION OF THE CENTRAL NERVOUS SYSTEM}

Leukemic cells regulate the expression of adhesion molecules to confer a pro-survival advantage against chemotherapy and to increase their invasiveness to extramedullary sites (Erbani et al., 2020; Barbier et al., 2020; Wang et al., 2018; Gaynes et al., 2017; Akers et al., 2011). Growing evidence suggests that leukemic cells invade and colonize the leptomeningeal microenvironment through specific adhesion and homing mechanisms (Figure 1B). Co-culture of ALL cell lines and primary B- and T-ALL cells with meningeal cells enhanced leukemic cell survival compared to leukemic cells incubated in the CSF suggesting the importance of leukemic and meningeal cellcell interactions in promoting ALL cell survival (Basile et al., 2020). In fact, Jonart et al., (2020), demonstrated that ALL cells adhere to meningeal cells and that cell-cell adhesion governs leukemic cell dormancy and resistance to chemotherapy. Importantly, disruption of the meningeal ALL adhesion with tMe6TREN (Tris [2-(dimethylamino)ethyl]amine) increased the efficacy of chemotherapy in the CNS in leukemia xenograft murine models (Jonart et al., 2020). Other studies demonstrated that B-ALL cells from children and B-ALL cell lines were adherent to astrocytes, choroid plexus fibroblasts, and epithelial cells, thus promoting leukemic cell survival and chemoresistance (Akers et al., 2011; Fernández-Sevilla et al., 2020).

Integrins and their ligands play a vital role in leukemic cells migration and homing through mediating cell-cell and cell-ECM adhesion (Scharff et al., 2020a). To date, few studies have identified specific adhesion molecules potentially associated with leukemia infiltration in the $\mathrm{CNS} /$ meninges. Increased expression of intercellular adhesion molecule 1 (ICAM-1) was correlated with CNS disease in pediatric ALL samples and B-ALL patient derived xenografts (Mielcarek et al., 1997; Holland et al., 2011). Furthermore, the expression of CD56, a neural celladhesion molecule (NCAM), was elevated in adult ALL samples with CNS involvement (Ravandi et al., 2002; Hu et al., 2017). NCAM was also associated with intracerebral and leptomeningeal infiltration in adult $\mathrm{T}$ cell leukemia (ATL) (Hashiguchi et al., 2002). Thus, NCAM was proposed as a marker for CNS infiltration and poor prognosis in ALL, and ATL. In addition, AML and ALL patients who had elevated levels of matrix metalloproteinase-9 (MMP-9) and soluble vascular cell adhesion molecule 1 (sVCAM-1) in CSF were at risk of CNS involvement (Si et al., 2015). 
Elegant studies by Yao et al.(2018), demonstrated that B-ALL cells invade the CNS along emissary vessels passing between vertebral and calvarial BM, and the subarachnoid space. ALL cells expressed integrin subunit alpha 6 (a6), a laminin receptor, which interacted with laminin expressed on the bridging vessels, thus mediating the migration of ALL cells into the meninges (Yao et al., 2018). ALL xenografts treated with specific a6 integrinneutralizing antibodies showed reduced leukemia burden in the $\mathrm{CSF} / \mathrm{meninges}$. High levels of Itga 6 mRNA (encodes a6) were also found in leukemic cells in a BCR-ABL1-driven murine model of meningeal leukemia ( $\mathrm{Yu}$ et al., 2019). On the contrary, recent studies identified ITGA5 (a5) and ITGA9 (a9) expression positively correlated with CSF colonization in primary B-ALL samples (Scharff et al., 2020a; Scharff et al., 2020b).

Functionally, co-culture of B-ALL Nalm6 cells with choroid plexus fibroblasts resulted in upregulation of VLA-4 and LFA-1 in leukemic cells concomitant with increased expression of relevant integrin ligands, VCAM1 and ICAM1, in the tested fibroblasts. The inhibition of VLA-4/VCAM-1 signaling with anti-VLA-4 antibodies sensitized co-cultured leukemic cells to chemotherapy (Fernández-Sevilla et al., 2020). Further studies are required to determine whether targeting VLA-4/VCAM-1 adhesion could be used to eradicate CNS involved leukemia. Other adherent junction proteins such as VE-cadherin and PECAM-1 increased the adhesion and migration of B-ALL cell lines through the human brain-derived microvascular endothelial cells but their role in CNS leukemia has yet to be determined (Akers et al., 2010). In another study, CCR7 was sufficient to drive leukemic cells to the CNS in T-ALL. Interestingly, gene expression analyses identified deregulation in genes encoding integrins and metalloproteases that could potentially interact with CCR7 function to support T-ALL invasion of the CNS (Buonamici et al., 2009). Moreover, recent studies showed that pediatric ALL-derived exosomes contributed to leukemic cell invasion in a model of the blood-cerebrospinal fluid barrier (BCSFB) in vitro. Interestingly, binding/uptake of ALL-derived exosomes was dependent on various exosomal integrins such as $\alpha \mathrm{V}, \alpha 5, \beta 1$, and $\beta 3$ (Erb et al., 2020).

\section{SUMMARY}

CNS involvement has been emerging as a major challenge in acute leukemia treatment. Patients with CNS infiltration have a low survival rate, particularly those with recurrent or refractory disease. The interaction between leukemic cells and the CNS microenvironment promotes leukemic cell quiescence and subsequently the resistance to chemotherapy. To date, few studies have investigated the roles of chemokine receptors and other molecules in leukemia trafficking to the CNS (Buonamici

\section{REFERENCES}

Akers, S. M., O’Leary, H. A., Minnear, F. L., Craig, M. D., Vos, J. A., Coad, J. E., et al. (2010). VE-cadherin and PECAM-1 Enhance ALL Migration across Brain et al., 2009; Williams et al., 2014; Jost et al., 2016; Williams et al., 2016; Alsadeq et al., 2017; Oruganti et al., 2017; Alsadeq et al., 2018; Prieto et al., 2018; Lenk et al., 2021). A growing body of evidence demonstrates that leukemic cells employ cell-cell and cell-ECM adhesion to reside and survive in the CNS/meninges. Furthermore, we speculate that metabolic reprogramming could provide leukemic cells with sufficient energy to facilitate the invasion and colonization of the nutrient-poor and hypoxic CNS microenvironment. Accordingly, targeting specific cell adhesion molecules and metabolic pathways could potentially increase treatment efficacy and reduce the toxicity of existing therapies. In fact, there are many drugs targeting metabolism or integrin-targeting drugs under clinical evaluation. However, those drugs have not yet been tested for the treatment of CNS involved leukemia. Moreover, the potential cross-talk between metabolic pathways and cell adhesion remains poorly understood, pointing to several questions: Are modifications in leukemic cell adhesion associated with specific energetic demands? Do cell adhesion mechanisms support metabolic rewiring of leukemic cells in the CNS niche? Do metabolic adaptations of leukemic cells lead to changes in cell-cell and cell-ECM adhesion within the CNS microenvironment? What is the role of meningeal fibroblasts and other cells within the CNS microenvironment in facilitating leukemia infiltration? Do they undergo further metabolic adaptations and/or express specific adhesion molecules to create a more permissive microenvironment for leukemia colonization? Further investigation is needed to uncover the specific adhesion molecules and metabolic adaptations underlying CNS disease and CNS relapse in leukemia.

\section{AUTHOR CONTRIBUTIONS}

NS reviewed the literature and wrote the manuscript with support from EK and KM-W. All authors have read and agreed to the published version of the manuscript.

\section{FUNDING}

This work was supported by Grant R01 CA237165 (to KM-W) from the National Cancer Institute at the National Institutes of Health and Gabrielle's Angel Foundation for Cancer Research.

\section{ACKNOWLEDGMENTS}

We acknowledge the Matlawska laboratory for helping in the preparation of this manuscript.

Microvascular Endothelial Cell Monolayers. Exp. Hematol. 38 (9), 733-743. doi:10.1016/j.exphem.2010.05.001

Akers, S. M., Rellick, S. L., Fortney, J. E., and Gibson, L. F. (2011). Cellular Elements of the Subarachnoid Space Promote ALL Survival during Chemotherapy. Leuk. Res. 35 (6), 705-711. doi:10.1016/j.leukres.2010.12.031 
Alakel, N., Stölzel, F., Mohr, B., Kramer, M., Oelschlägel, U., Röllig, C., et al. (2017). Symptomatic central Nervous System Involvement in Adult Patients with Acute Myeloid Leukemia. Cmar 9, 97-102. doi:10.2147/cmar.s125259

Allard, M. F., Schonekess, B. O., Henning, S. L., English, D. R., and Lopaschuk, G. D. (1994). Contribution of Oxidative Metabolism and Glycolysis to ATP Production in Hypertrophied Hearts. Am. J. Physiology-Heart Circulatory Physiol. 267 (2), H742-H750. doi:10.1152/ajpheart.1994.267.2.h742

Alsadeq, A., Fedders, H., Vokuhl, C., Belau, N. M., Zimmermann, M., Wirbelauer, T., et al. (2017). The Role of ZAP70 Kinase in Acute Lymphoblastic Leukemia Infiltration into the central Nervous System. Haematologica 102 (2), 346-355. doi:10.3324/haematol.2016.147744

Alsadeq, A., Lenk, L., Vadakumchery, A., Cousins, A., Vokuhl, C., Khadour, A., et al. (2018). IL7R Is Associated with CNS Infiltration and Relapse in Pediatric B-Cell Precursor Acute Lymphoblastic Leukemia. Blood 132 (15), 1614-1617. doi:10.1182/blood-2018-04-844209

Anderson, N. M., Mucka, P., Kern, J. G., and Feng, H. (2018). The Emerging Role and Targetability of the TCA Cycle in Cancer Metabolism. Protein Cell 9 (2), 216-237. doi:10.1007/s13238-017-0451-1

Barbier, V., Erbani, J., Fiveash, C., Davies, J. M., Tay, J., Tallack, M. R., et al. (2020). Endothelial E-Selectin Inhibition Improves Acute Myeloid Leukaemia Therapy by Disrupting Vascular Niche-Mediated Chemoresistance. Nat. Commun. 11 (1), 2042. doi:10.1038/s41467-020-15817-5

Bartram, J., Goulden, N., Wright, G., Adams, S., Brooks, T., Edwards, D., et al. (2018). High Throughput Sequencing in Acute Lymphoblastic Leukemia Reveals Clonal Architecture of central Nervous System and Bone Marrow Compartments. Haematologica 103 (3), e110-e114. doi:10.3324/ haematol.2017.174987

Basile, P., Jonart, L. M., Ebadi, M., Johnson, K., Kerfeld, M., and Gordon, P. M. (2020). The Meninges Enhance Leukaemia Survival in Cerebral Spinal Fluid. Br. J. Haematol. 189 (3), 513-517. doi:10.1111/bjh.16270

Basu, S. K., Remick, S. C., Monga, M., and Gibson, L. F. (2014). Breaking and Entering into the CNS: Clues from Solid Tumor and Nonmalignant Models with Relevance to Hematopoietic Malignancies. Clin. Exp. Metastasis 31 (2), 257-267. doi:10.1007/s10585-013-9623-4

Battisti, V., Maders, L. D., Bagatini, M. D., Santos, K. F., Spanevello, R. M., Maldonado, P. A., et al. (2008). Measurement of Oxidative Stress and Antioxidant Status in Acute Lymphoblastic Leukemia Patients. Clin. Biochem. 41 (7-8), 511-518. doi:10.1016/j.clinbiochem.2008.01.027

Baysal, B. E. (2007). A Recurrent Stop-Codon Mutation in Succinate Dehydrogenase Subunit B Gene in normal Peripheral Blood and Childhood T-Cell Acute Leukemia. PLoS One 2 (5), e436. doi:10.1371/ journal.pone. 0000436

Bhanot, H., Weisberg, E. L., Reddy, M. M., Nonami, A., Neuberg, D., Stone, R. M., et al. (2017). Acute Myeloid Leukemia Cells Require 6-phosphogluconate Dehydrogenase for Cell Growth and NADPH-dependent Metabolic Reprogramming. Oncotarget 8 (40), 67639-67650. doi:10.18632/ oncotarget. 18797

Bleyer, W. A. (1984). Intrathecal Methotrexate versus central Nervous System Leukemia. Cancer Drug Deliv. 1 (2), 157-167. doi:10.1089/cdd.1984.1.157

Boag, J. M., Beesley, A. H., Firth, M. J., Freitas, J. R., Ford, J., Hoffmann, K., et al. (2006). Altered Glucose Metabolism in Childhood Pre-B Acute Lymphoblastic Leukaemia. Leukemia 20 (10), 1731-1737. doi:10.1038/sj.leu.2404365

Buonamici, S., Trimarchi, T., Ruocco, M. G., Reavie, L., Cathelin, S., Mar, B. G., et al. (2009). CCR7 Signalling as an Essential Regulator of CNS Infiltration in T-Cell Leukaemia. Nature 459 (7249), 1000-1004. doi:10.1038/nature08020

Cairns, R. A., Harris, I. S., and Mak, T. W. (2011). Regulation of Cancer Cell Metabolism. Nat. Rev. Cancer 11 (2), 85-95. doi:10.1038/nrc2981

Calviño, E., Estañ, M. C., Sánchez-Martín, C., Brea, R., de Blas, E., Boyano-Adánez Mdel, C., et al. (2014). Regulation of Death Induction and Chemosensitizing Action of 3-bromopyruvate in Myeloid Leukemia Cells: Energy Depletion, Oxidative Stress, and Protein Kinase Activity Modulation. J. Pharmacol. Exp. Ther. 348 (2), 324-335. doi:10.1124/jpet.113.206714

Cassileth, P. A., Sylvester, L. S., Bennett, J. M., and Begg, C. B. (1988). High Peripheral Blast Count in Adult Acute Myelogenous Leukemia Is a Primary Risk Factor for CNS Leukemia. Jco 6 (3), 495-498. doi:10.1200/jco.1988.6.3.495

Cha, J.-Y., and Lee, H.-J. (2016). Targeting Lipid Metabolic Reprogramming as Anticancer Therapeutics. J. Cancer Prev. 21 (4), 209-215. doi:10.15430/ jcp.2016.21.4.209
Chang, H., Brandwein, J., yi, Q.-L., Chun, K., Patterson, B., and Brien, B. (2004). Extramedullary Infiltrates of AML Are Associated with CD56 Expression, 11q23 Abnormalities and Inferior Clinical Outcome. Leuk. Res. 28 (10), 1007-1011. doi:10.1016/j.leukres.2004.01.006

Chaturvedi, A., Araujo Cruz, M. M., Jyotsana, N., Sharma, A., Yun, H., Görlich, K., et al. (2013). Mutant IDH1 Promotes Leukemogenesis In Vivo and Can Be Specifically Targeted in Human AML. J. Am. Soc. Hematol. 122 (16), 2877-2887. doi:10.1182/blood-2013-03-491571

Cheng, C. L., Li, C. C., Hou, H. A., Fang, W. Q., Chang, C. H., Lin, C. T., et al. (2015). Risk Factors and Clinical Outcomes of Acute Myeloid Leukaemia with central Nervous System Involvement in Adults. BMC cancer 15 (1), 344-354. doi:10.1186/s12885-015-1376-9

Chou, W.-C., Lei, W.-C., Ko, B.-S., Hou, H.-A., Chen, C.-Y., Tang, J.-L., et al. (2011). The Prognostic Impact and Stability of Isocitrate Dehydrogenase 2 Mutation in Adult Patients with Acute Myeloid Leukemia. Leukemia 25 (2), 246-253. doi:10.1038/leu.2010.267

Ciarcia, R., d'Angelo, D., Pacilio, C., Pagnini, D., Galdiero, M., Fiorito, F., et al. (2010). Dysregulated Calcium Homeostasis and Oxidative Stress in Chronic Myeloid Leukemia (CML) Cells. J. Cel. Physiol. 224 (2), 443-453. doi:10.1002/ jcp. 22140

Colmone, A., Amorim, M., Pontier, A. L., Wang, S., Jablonski, E., and Sipkins, D. A. (2008). Leukemic Cells Create Bone Marrow Niches that Disrupt the Behavior of normal Hematopoietic Progenitor Cells. Science 322 (5909), 1861-1865. doi:10.1126/science. 1164390

Cortes, J. (2001). Central Nervous System Involvement in Adult Acute Lymphocytic Leukemia. Hematology/oncology Clin. North America 15 (1), 145-162. doi:10.1016/s0889-8588(05)70203-3

DeBerardinis, R. J., and Chandel, N. S. (2016). Fundamentals of Cancer Metabolism. Sci. Adv. 2 (5), e1600200. doi:10.1126/sciadv.1600200

Del Principe, M. I., Buzzatti, E., Piciocchi, A., Forghieri, F., Bonifacio, M., Lessi, F., et al. (2021). Clinical Significance of Occult central Nervous System Disease in Adult Acute Lymphoblastic Leukemia. A Multicenter Report from the Campus ALL Network. Haematologica 106 (1), 39-45. doi:10.3324/ haematol.2019.231704

Del Principe, M. I., Maurillo, L., Buccisano, F., Sconocchia, G., Cefalo, M., De Santis, G., et al. (2014). Central Nervous System Involvement in Adult Acute Lymphoblastic Leukemia: Diagnostic Tools, Prophylaxis and Therapy. Mediterr. J. Hematol. Infect. Dis. 6 (1), e2014075. doi:10.4084/mjhid.2014.075

Di Martino, L., Tosello, V., Peroni, E., and Piovan, E. (2021). Insights on Metabolic Reprogramming and its Therapeutic Potential in Acute Leukemia. Int. J. Mol. Sci. 22 (16). doi:10.3390/ijms 22168738

Erb, U., Hikel, J., Meyer, S., Ishikawa, H., Worst, T. S., Nitschke, K., et al. (2020). The Impact of Small Extracellular Vesicles on Lymphoblast Trafficking across the Blood-Cerebrospinal Fluid Barrier In Vitro. Int. J. Mol. Sci. 21 (15). doi:10.3390/ijms21155491

Erbani, J., Tay, J., Barbier, V., Levesque, J.-P., and Winkler, I. G. (2020). Acute Myeloid Leukemia Chemo-Resistance Is Mediated by E-Selectin Receptor CD162 in Bone Marrow Niches. Front. Cel Dev. Biol. 8, 668. doi:10.3389/ fcell.2020.00668

Fathi, A. T., Sadrzadeh, H., Borger, D. R., Ballen, K. K., Amrein, P. C., Attar, E. C., et al. (2012). Prospective Serial Evaluation of 2-hydroxyglutarate, during Treatment of Newly Diagnosed Acute Myeloid Leukemia, to Assess Disease Activity and Therapeutic Response. Blood J. Am. Soc. Hematol. 120 (23), 4649-4652. doi:10.1182/blood-2012-06-438267

Fernández-Sevilla, L. M., Valencia, J., Flores-Villalobos, M. A., Gonzalez-Murillo, Á., Sacedón, R., Jiménez, E., et al. (2020). The Choroid Plexus Stroma Constitutes a Sanctuary for Paediatric B-Cell Precursor Acute Lymphoblastic Leukaemia in the central Nervous System. J. Pathol. 252 (2), 189-200. doi:10.1002/path.5510

Figueroa, M. E., Abdel-Wahab, O., Lu, C., Ward, P. S., Patel, J., Shih, A., et al. (2010). Leukemic IDH1 and IDH2 Mutations Result in a Hypermethylation Phenotype, Disrupt TET2 Function, and Impair Hematopoietic Differentiation. Cancer cell 18 (6), 553-567. doi:10.1016/j.ccr.2010.11.015

Fonseca, I. C. C. F. E., da Luz, F. A. C., Uehara, I. A., and Silva, M. J. B. (2018). Celladhesion Molecules and Their Soluble Forms: Promising Predictors of "tumor Progression" and Relapse in Leukemia. Tumour Biol. 40 (11), 1010428318811525. doi:10.1177/1010428318811525 
Frishman-Levy, L., and Izraeli, S. (2017). Advances in Understanding the Pathogenesis of CNS Acute Lymphoblastic Leukaemia and Potential for Therapy. Br. J. Haematol. 176 (2), 157-167. doi:10.1111/bjh.14411

Galati, D., Di Noto, R., and Del Vecchio, L. (2013). Diagnostic Strategies to Investigate Cerebrospinal Fluid Involvement in Haematological Malignancies. Leuk. Res. 37 (3), 231-237. doi:10.1016/j.leukres.2012.11.016

Gaynes, J. S., Jonart, L. M., Zamora, E. A., Naumann, J. A., Gossai, N. P., and Gordon, P. M. (2017). The central Nervous System Microenvironment Influences the Leukemia Transcriptome and Enhances Leukemia ChemoResistance. Haematologica 102 (4), e136-e139. doi:10.3324/ haematol.2016.152926

Giambra, V., Jenkins, C. E., Lam, S. H., Hoofd, C., Belmonte, M., Wang, X., et al. (2015). Leukemia Stem Cells in T-ALL Require Active Hifla and Wnt Signaling. Blood 125 (25), 3917-3927. doi:10.1182/blood-2014-10-609370

Glait-Santar, C., Desmond, R., Feng, X., Bat, T., Chen, J., Heuston, E., et al. (2015). Functional Niche Competition between Normal Hematopoietic Stem and Progenitor Cells and Myeloid Leukemia Cells. Stem Cells 33 (12), 3635-3642. doi:10.1002/stem.2208

Gökbuget, N., and Hoelzer, D. (1998). Meningeosis Leukaemica in Adult Acute Lymphoblastic Leukaemia. J. Neurooncol. 38 (2), 167-180.

Gossai, N. P., and Gordon, P. M. (2017). The Role of the Central Nervous System Microenvironment in Pediatric Acute Lymphoblastic Leukemia. Front. Pediatr. 5, 90. doi:10.3389/fped.2017.00090

Gregory, M. A., Nemkov, T., Park, H. J., Zaberezhnyy, V., Gehrke, S., Adane, B., et al. (2019). Targeting Glutamine Metabolism and Redox State for Leukemia Therapy. Clin. Cancer Res. 25 (13), 4079-4090. doi:10.1158/1078-0432.ccr-183223

Guan, Y., Gerhard, B., and Hogge, D. E. (2003). Detection, Isolation, and Stimulation of Quiescent Primitive Leukemic Progenitor Cells from Patients with Acute Myeloid Leukemia (AML). Blood 101 (8), 3142-3149. doi:10.1182/ blood-2002-10-3062

Gutjahr, J. C., Bayer, E., Yu, X., Laufer, J. M., Höpner, J. P., Tesanovic, S., et al. (2021). CD44 Engagement Enhances Acute Myeloid Leukemia Cell Adhesion to the Bone Marrow Microenvironment by Increasing VLA-4 Avidity. Haematologica 106 (8), 2102-2113. doi:10.3324/haematol.2019.231944

Han, L., Cavazos, Antonio., Baran, Natalia., Zhang, Qi., Kuruvilla, Vinitha. Mary., Gay, Jason. P., et al. (2019). Mitochondrial Oxphos as Survival Mechanism of Minimal Residual AML Cells after Induction Chemotherapy: Survival Benefit by Complex I Inhibition with Iacs-010759. Am. Soc. Hematol. Wash. DC 134, 5161. doi:10.1182/blood-2019-124475

Hanahan, D., and Weinberg, R. A. (2011). Hallmarks of Cancer: the Next Generation. Cell 144 (5), 646-674. doi:10.1016/j.cell.2011.02.013

Härzschel, A., Zucchetto, A., Gattei, V., and Hartmann, T. N. (2020). VLA-4 Expression and Activation in B Cell Malignancies: Functional and Clinical Aspects. Int. J. Mol. Sci. 21 (6). doi:10.3390/ijms21062206

Haselbeck, R. J., and McAlister-Henn, L. (1993). Function and Expression of Yeast Mitochondrial NAD- and NADP-specific Isocitrate Dehydrogenases. J. Biol. Chem. 268 (16), 12116-12122. doi:10.1016/s0021-9258(19)50315-5

Hashiguchi, T., Tara, M., Niina, K., Higuchi, I., Arimura, K., Osame, M., et al. (2002). Adult T-Cell Leukemia (ATL) Cells Which Express Neural Cell Adhesion Molecule (NCAM) and Infiltrate into the central Nervous System. Intern. Med. 41 (1), 34-38. doi:10.2169/internalmedicine.41.34

Heath, J. L., Cohn, G. M., Zaidi, S. K., and Stein, G. S. (2019). The Role of Cell Adhesion in Hematopoiesis and Leukemogenesis. J. Cel Physiol 234 (11), 19189-19198. doi:10.1002/jcp.28636

Heidari, N., Saki, N., De Filippis, L., Shahjahani, M., Teimouri, A., and Ahmadzadeh, A. (2016). Central Nervous System Niche Involvement in the Leukemia. Clin. Transl Oncol. 18 (3), 240-250. doi:10.1007/s12094-015-1370-3

Herranz, D., Ambesi-Impiombato, A., Sudderth, J., Sánchez-Martín, M., Belver, L., Tosello, V., et al. (2015). Metabolic Reprogramming Induces Resistance to AntiNOTCH1 Therapies in T Cell Acute Lymphoblastic Leukemia. Nat. Med. 21 (10), 1182-1189. doi:10.1038/nm.3955

Herst, P. M., Howman, R. A., Neeson, P. J., Berridge, M. V., and Ritchie, D. S. (2011). The Level of Glycolytic Metabolism in Acute Myeloid Leukemia Blasts at Diagnosis Is Prognostic for Clinical Outcome. J. Leukoc. Biol. 89 (1), 51-55. doi:10.1189/jlb.0710417

Hole, P. S., Zabkiewicz, J., Munje, C., Newton, Z., Pearn, L., White, P., et al. (2013). Overproduction of NOX-Derived ROS in AML Promotes Proliferation and Is
Associated with Defective Oxidative Stress Signaling. Blood 122 (19), 3322-3330. doi:10.1182/blood-2013-04-491944

Holland, J. F., Hong, W. K., and Research, A. A. f. C. (2003). Holland-frei Cancer Medicine, 8. People's Medical Publishing House USA Limited PMPH. Cancer Medicine 8).

Holland, M., Castro, F. V., Alexander, S., Smith, D., Liu, J., Walker, M., et al. (2011). RAC2, AEP, and ICAM1 Expression Are Associated with CNS Disease in a Mouse Model of Pre-B Childhood Acute Lymphoblastic Leukemia. Blood 118 (3), 638-649. doi:10.1182/blood-2010-09-307330

Holmes, R., Keating, M. J., Cork, A., Broach, Y., Trujillo, J., Dalton, W. T., et al. (1985). A Unique Pattern of central Nervous System Leukemia in Acute Myelomonocytic Leukemia Associated with Inv (16)(p13q22). Blood 65 (5), 1071-1078.

Hu, W., Wang, X., Yang, R., Bi, L., Xie, Y., Zhang, Z., et al. (2017). Expression of CD56 Is a Risk Factor for Acute Lymphocytic Leukemia with central Nervous System Involvement in Adults. Hematology 22 (2), 81-87. doi:10.1080/ 10245332.2016.1238183

Hunger, S. P., Lu, X., Devidas, M., Camitta, B. M., Gaynon, P. S., Winick, N. J., et al. (2012). Improved Survival for Children and Adolescents with Acute Lymphoblastic Leukemia between 1990 and 2005: a Report from the Children's Oncology Group. Jco 30 (14), 1663-1669. doi:10.1200/jco.2011.37.8018

Ito, H., Nakamae, I., Kato, J. Y., and Yoneda-Kato, N. (2021). Stabilization of Fatty Acid Synthesis Enzyme Acetyl-CoA Carboxylase 1 Suppresses Acute Myeloid Leukemia Development. J. Clin. Invest. 131 (12). doi:10.1172/JCI141529

Jacamo, R., Chen, Y., Wang, Z., Ma, W., Zhang, M., Spaeth, E. L., et al. (2014). Reciprocal Leukemia-Stroma VCAM-1/vla-4-dependent Activation of NF-Kb Mediates Chemoresistance. Blood 123 (17), 2691-2702. doi:10.1182/blood2013-06-511527

Jacque, N., Ronchetti, A. M., Larrue, C., Meunier, G., Birsen, R., Willems, L., et al. (2015). Targeting Glutaminolysis Has Antileukemic Activity in Acute Myeloid Leukemia and Synergizes with BCL-2 Inhibition. Blood 126 (11), 1346-1356. doi:10.1182/blood-2015-01-621870

Jonart, L. M., Ebadi, M., Basile, P., Johnson, K., Makori, J., and Gordon, P. M. (2020). Disrupting the Leukemia Niche in the central Nervous System Attenuates Leukemia Chemoresistance. Haematologica 105 (8), 2130-2140. doi:10.3324/haematol.2019.230334

Jones, C. L., Stevens, B. M., D’Alessandro, A., Reisz, J. A., Culp-Hill, R., Nemkov, T., et al. (2018). Inhibition of Amino Acid Metabolism Selectively Targets Human Leukemia Stem Cells. Cancer Cell 34 (5), 724-740. doi:10.1016/j.ccell.2018.10.005

Jost, T. R., Borga, C., Radaelli, E., Romagnani, A., Perruzza, L., Omodho, L., et al. (2016). Role of CXCR4-Mediated Bone Marrow Colonization in CNS Infiltration by T Cell Acute Lymphoblastic Leukemia. J. Leukoc. Biol. 99 (6), 1077-1087. doi:10.1189/jlb.5ma0915-394r

Kato, I., Nishinaka, Y., Nakamura, M., Akarca, A. U., Niwa, A., Ozawa, H., et al. (2017). Hypoxic Adaptation of Leukemic Cells Infiltrating the CNS Affords a Therapeutic Strategy Targeting VEGFA. Blood 129 (23), 3126-3129. doi:10.1182/blood-2016-06-721712

Khan, A. U. H., Rathore, M. G., Allende-Vega, N., Vo, D.-N., Belkhala, S., Orecchioni, S., et al. (2016). Human Leukemic Cells Performing Oxidative Phosphorylation (OXPHOS) Generate an Antioxidant Response Independently of Reactive Oxygen Species (ROS) Production. EBioMedicine 3, 43-53. doi:10.1016/j.ebiom.2015.11.045

Kishton, R. J., Barnes, C. E., Nichols, A. G., Cohen, S., Gerriets, V. A., Siska, P. J., et al. (2016). AMPK Is Essential to Balance Glycolysis and Mitochondrial Metabolism to Control T-ALL Cell Stress and Survival. Cel Metab. 23 (4), 649-662. doi:10.1016/j.cmet.2016.03.008

Kouser, S., and Hashmi, K. Z. (2007). Frequency of central Nervous System Involvement in Acute Myeloid Leukemia. J. Coll. Physicians Surg. Pak 17 (6), 378-379. 06.2007/JCPSP.378379.

Kuntz, E. M., Baquero, P., Michie, A. M., Dunn, K., Tardito, S., Holyoake, T. L., et al. (2017). Targeting Mitochondrial Oxidative Phosphorylation Eradicates Therapy-Resistant Chronic Myeloid Leukemia Stem Cells. Nat. Med. 23 (10), 1234-1240. doi:10.1038/nm.4399

Lazarus, H. M., Richards, S. M., Chopra, R., Litzow, M. R., Burnett, A. K., Wiernik, P. H., et al. (2006). Central Nervous System Involvement in Adult Acute Lymphoblastic Leukemia at Diagnosis: Results from the International All Trial MRC UKALL XII/ECOG E2993. Blood 108 (2), 465-472. doi:10.1182/blood2005-11-4666 
Lee, D. Y., Xun, Z., Platt, V., Budworth, H., Canaria, C. A., and McMurray, C. T. (2013). Distinct Pools of Non-glycolytic Substrates Differentiate Brain Regions and Prime Region-specific Responses of Mitochondria. PLoS One 8 (7), e68831. doi:10.1371/journal.pone.0068831

Lenk, L., Alsadeq, A., and Schewe, D. M. (2020). Involvement of the central Nervous System in Acute Lymphoblastic Leukemia: Opinions on Molecular Mechanisms and Clinical Implications Based on Recent Data. Cancer Metastasis Rev. 39 (1), 173-187. doi:10.1007/s10555-020-09848-Z

Lenk, L., Carlet, M., Vogiatzi, F., Spory, L., Winterberg, D., Cousins, A., et al. (2021). CD79a Promotes CNS-Infiltration and Leukemia Engraftment in Pediatric B-Cell Precursor Acute Lymphoblastic Leukemia. Commun. Biol. 4 (1), 73. doi:10.1038/s42003-020-01591-Z

Liu, T., Kishton, R. J., Macintyre, A. N., Gerriets, V. A., Xiang, H., Liu, X., et al. (2014). Glucose Transporter 1-mediated Glucose Uptake Is Limiting for B-Cell Acute Lymphoblastic Leukemia Anabolic Metabolism and Resistance to Apoptosis. Cell Death Dis 5, e1470. doi:10.1038/cddis.2014.431

Loeb, K. R., Cherian, S., Becker, P. S., Walter, R. B., Pagel, J. M., Abkowitz, J. L., et al. (2016). Comparative Analysis of Flow Cytometry and Morphology for the Detection of Acute Myeloid Leukaemia Cells in Cerebrospinal Fluid. Br. J. Haematol. 172 (1), 134-136. doi:10.1111/bjh.13465

Lucarelli, G., Galleggiante, V., Rutigliano, M., Sanguedolce, F., Cagiano, S., Bufo, P., et al. (2015). Metabolomic Profile of Glycolysis and the Pentose Phosphate Pathway Identifies the central Role of Glucose-6-Phosphate Dehydrogenase in clear Cell-Renal Cell Carcinoma. Oncotarget 6 (15), 13371-13386. doi:10.18632/oncotarget.3823

Lyengar, V., and Shimanovsky, A. (2021). "Leukemia," in StatPearls (Treasure Island (FL.

Marks, D. I., Paietta, E. M., Moorman, A. V., Richards, S. M., Buck, G., DeWald, G., et al. (2009). T-cell Acute Lymphoblastic Leukemia in Adults: Clinical Features, Immunophenotype, Cytogenetics, and Outcome from the Large Randomized Prospective Trial (UKALL XII/ECOG 2993). Blood 114 (25), 5136-5145. doi:10.1182/blood-2009-08-231217

Martin, T. A., Ye, L., Sanders, A. J., Lane, J., and Jiang, W. G. (2013). "Cancer Invasion and Metastasis: Molecular and Cellular Perspective," in Madame Curie Bioscience Database (Austin, TX: Landes Bioscience). [Internet].

Martínez-Laperche, C., Gómez-García, A. M., Lassaletta, Á., Moscardó, C., Vivanco, J. L., Molina, J., et al. (2013). Detection of Occult Cerebrospinal Fluid Involvement during Maintenance Therapy Identifies a Group of Children with Acute Lymphoblastic Leukemia at High Risk for Relapse. Am. J. Hematol. 88 (5), 359-364. doi:10.1002/ajh.23407

Matre, P., Velez, J., Jacamo, R., Qi, Y., Su, X., Cai, T., et al. (2016). Inhibiting Glutaminase in Acute Myeloid Leukemia: Metabolic Dependency of Selected AML Subtypes. Oncotarget 7 (48), 79722-79735. doi:10.18632/ oncotarget.12944

Matthijssens, F., Sharma, N. D., Nysus, M., Nickl, C. K., Kang, H., Perez, D. R., et al. (2021). RUNX2 Regulates Leukemic Cell Metabolism and Chemotaxis in HighRisk T Cell Acute Lymphoblastic Leukemia. J. Clin. Invest. 131 (6), e141566. doi:10.1172/JCI141566

Mielcarek, M., Sperling, C., Shrappe, M., Meyer, U., Riehm, H., and Ludwig, W.-D. (1997). Expression of Intercellular Adhesion Molecule 1 (ICAM-1) in Childhood Acute Lymphoblastic Leukaemia: Correlation with Clinical Features and Outcome. Br. J. Haematol. 96 (2), 301-307. doi:10.1046/j.13652141.1997.d01-2019.x

Moharram, S. A., Shah, K., and Kazi, J. U. (2017). T-cell Acute Lymphoblastic Leukemia Cells Display Activation of Different Survival Pathways. J. Cancer 8 (19), 4124. doi:10.7150/jca.21725

More, T. H., RoyChoudhury, S., Christie, J., Taunk, K., Mane, A., Santra, M. K., et al. (2018). Metabolomic Alterations in Invasive Ductal Carcinoma of Breast: A Comprehensive Metabolomic Study Using Tissue and Serum Samples. Oncotarget 9 (2), 2678-2696. doi:10.18632/oncotarget.23626

Musharraf, S. G., Siddiqui, A. J., Shamsi, T., and Naz, A. (2017). SERUM Metabolomics of Acute Lymphoblastic Leukaemia and Acute Myeloid Leukaemia for Probing Biomarker Molecules. Hematological Oncol. 35 (4), 769-777. doi:10.1002/hon.2313

Nachmias, B., and Schimmer, A. D. (2018). Metabolic Flexibility in LeukemiaAdapt or Die. Cancer Cell 34 (5), 695-696. doi:10.1016/j.ccell.2018.10.012

Nepstad, I., Reikvam, H., Brenner, A. K., Bruserud, Ø., and Hatfield, K. J. (2018). Resistance to the Antiproliferative In Vitro Effect of PI3K-Akt-mTOR
Inhibition in Primary Human Acute Myeloid Leukemia Cells Is Associated with Altered Cell Metabolism. Int. J. Mol. Sci. 19 (2). doi:10.3390/ijms19020382

Ninomiya, M., Abe, A., Katsumi, A., Xu, J., Ito, M., Arai, F., et al. (2007). Homing, Proliferation and Survival Sites of Human Leukemia Cells In Vivo in Immunodeficient Mice. Leukemia 21 (1), 136-142. doi:10.1038/sj.leu.2404432 Oruganti, S. R., Torres, D. J., Krebsbach, S., Asperti-Boursin, F., Winters, J., Matlawska-Wasowska, K., et al. (2017). CARMA1 Is a Novel Regulator of T-ALL Disease and Leukemic Cell Migration to the CNS. Leukemia 31 (1), 255-258. doi:10.1038/leu.2016.272

Peng, C. T., Wu, K. H., Lan, S. J., Tsai, J. J. P., Tsai, F. J., and Tsai, C. H. (2005). Amino Acid Concentrations in Cerebrospinal Fluid in Children with Acute Lymphoblastic Leukemia Undergoing Chemotherapy. Eur. J. Cancer 41 (8), 1158-1163. doi:10.1016/j.ejca.2005.02.013

Pinkel, D., and Woo, S. (1994). Prevention and Treatment of Meningeal Leukemia in Children.

Piovan, E., Tosello, V., Amadori, A., and Zanovello, P. (2018). Chemotactic Cues for NOTCH1-dependent Leukemia. Front. Immunol. 9, 633. doi:10.3389/ fimmu.2018.00633

Pitt, L. A., Tikhonova, A. N., Hu, H., Trimarchi, T., King, B., Gong, Y., et al. (2015). CXCL12-Producing Vascular Endothelial Niches Control Acute T Cell Leukemia Maintenance. Cancer Cell 27 (6), 755-768. doi:10.1016/j.ccell.2015.05.002

Pochedly, C. (1977). Neurotoxicity Due to CNS Therapy for Leukemia. Med. Pediatr. Oncol. 3 (1), 101-115. doi:10.1002/mpo.2950030114

Poulain, L., Sujobert, P., Zylbersztejn, F., Barreau, S., Stuani, L., Lambert, M., et al. (2017). High mTORC1 Activity Drives Glycolysis Addiction and Sensitivity to G6PD Inhibition in Acute Myeloid Leukemia Cells. Leukemia 31 (11), 2326-2335. doi:10.1038/leu.2017.81

Prieto, C., López-Millán, B., Roca-Ho, H., Stam, R. W., Romero-Moya, D., Rodríguez-Baena, F. J., et al. (2018). NG2 Antigen Is Involved in Leukemia Invasiveness and central Nervous System Infiltration in MLL-Rearranged Infant B-ALL. Leukemia 32 (3), 633-644. doi:10.1038/leu.2017.294

Raffel, S., Falcone, M., Kneisel, N., Hansson, J., Wang, W., Lutz, C., et al. (2017). BCAT1 Restricts aKG Levels in AML Stem Cells Leading to IDHmut-like DNA Hypermethylation. Nature 551 (7680), 384-388. doi:10.1038/nature24294

Rashkovan, M., and Ferrando, A. (2019). Metabolic Dependencies and Vulnerabilities in Leukemia. Genes Dev. 33 (21-22), 1460-1474. doi:10.1101/ gad.326470.119

Ravandi, F., Cortes, J., Estrov, Z., Thomas, D., Giles, F. J., Huh, Y. O., et al. (2002). CD56 Expression Predicts Occurrence of CNS Disease in Acute Lymphoblastic Leukemia. Leuk. Res. 26 (7), 643-649. doi:10.1016/s0145-2126(01)00188-6

Ribeiro, D., Melão, A., van Boxtel, R., Santos, C. I., Silva, A., Silva, M. C., et al. (2018). STAT5 Is Essential for IL-7-mediated Viability, Growth, and Proliferation of T-Cell Acute Lymphoblastic Leukemia Cells. Blood Adv. 2 (17), 2199-2213. doi:10.1182/bloodadvances.2018021063

Riganti, C., Gazzano, E., Polimeni, M., Aldieri, E., and Ghigo, D. (2012). The Pentose Phosphate Pathway: an Antioxidant Defense and a Crossroad in Tumor Cell Fate. Free Radic. Biol. Med. 53 (3), 421-436. doi:10.1016/ j.freeradbiomed.2012.05.006

Robinson, A. J., Davies, S., Darley, R. L., and Tonks, A. (2021). Reactive Oxygen Species Rewires Metabolic Activity in Acute Myeloid Leukemia. Front. Oncol. 11, 632623. doi:10.3389/fonc.2021.632623

Robinson, A. J., Hopkins, G. L., Rastogi, N., Hodges, M., Doyle, M., Davies, S., et al. (2020). Reactive Oxygen Species Drive Proliferation in Acute Myeloid Leukemia via the Glycolytic Regulator PFKFB3. Cancer Res. 80 (5), 937-949. doi:10.1158/0008-5472.can-19-1920

Rowe, J. M., and Tallman, M. S. (2010). How I Treat Acute Myeloid Leukemia. Blood 116 (17), 3147-3156. doi:10.1182/blood-2010-05-260117

Rozovski, U., Ohanian, M., Ravandi, F., Garcia-Manero, G., Faderl, S., Pierce, S., et al. (2015). Incidence of and Risk Factors for Involvement of the central Nervous System in Acute Myeloid Leukemia. Leuk. Lymphoma 56 (5), 1392-1397. doi:10.3109/10428194.2014.953148

Rubnitz, J. E. (2017). Current Management of Childhood Acute Myeloid Leukemia. Pediatr. Drugs 19 (1), 1-10. doi:10.1007/s40272-016-0200-6

Sabharwal, S. S., and Schumacker, P. T. (2014). Mitochondrial ROS in Cancer: Initiators, Amplifiers or an Achilles' Heel. Nat. Rev. Cancer 14 (11), 709-721. doi:10.1038/nrc3803

Sallmyr, A., Fan, J., and Rassool, F. V. (2008). Genomic Instability in Myeloid Malignancies: Increased Reactive Oxygen Species (ROS), DNA Double Strand 
Breaks (DSBs) and Error-Prone Repair. Cancer Lett. 270 (1), 1-9. doi:10.1016/ j.canlet.2008.03.036

Savino, A. M., Fernandes, S. I., Olivares, O., Zemlyansky, A., Cousins, A., Markert, E. K., et al. (2020). Metabolic Adaptation of Acute Lymphoblastic Leukemia to the central Nervous System Microenvironment Depends on Stearoyl-CoA Desaturase. Nat. Cancer 1 (10), 998-1009. doi:10.1038/s43018-020-00115-2

Scharff, B. F. S. S., Modvig, S., Marquart, H. V., and Christensen, C. (2020a). Integrin-Mediated Adhesion and Chemoresistance of Acute Lymphoblastic Leukemia Cells Residing in the Bone Marrow or the Central Nervous System. Front. Oncol. 10, 775. doi:10.3389/fonc.2020.00775

Scharff, B. F. S. S., Modvig, S., Thastrup, M., Levinsen, M., Degn, M., Ryder, L. P., et al. (2020b). A Comprehensive Clinical Study of Integrins in Acute Lymphoblastic Leukemia Indicates a Role of a6/CD49f in Persistent Minimal Residual Disease and a5 in the Colonization of Cerebrospinal Fluid. Leuk Lymphoma 61 (7), 1714-1718. doi:10.1080/10428194.2020.1731500

Si, M.-Y., Fan, Z.-C., Li, Y.-Z., Chang, X.-L., Xie, Q.-D., and Jiao, X.-Y. (2015). The Prognostic Significance of Serum and Cerebrospinal Fluid MMP-9, CCL2 and sVCAM-1 in Leukemia CNS Metastasis. J. Neurooncol. 122 (2), 229-244. doi:10.1007/s11060-014-1707-8

Si, M., Jiao, X., Li, Y., Chen, H., He, P., and Jiang, F. (2018). The Role of Cytokines and Chemokines in the Microenvironment of the Blood-Brain Barrier in Leukemia central Nervous System Metastasis. Cmar Vol. 10, 305-313. doi:10.2147/cmar.s152419

Silva, A., Laranjeira, A. B. A., Martins, L. R., Cardoso, B. A., Demengeot, J., Yunes, J. A., et al. (2011). IL-7 Contributes to the Progression of Human T-Cell Acute Lymphoblastic Leukemias. Cancer Res. 71 (14), 4780-4789. doi:10.1158/00085472.can-10-3606

Sousa, B., Pereira, J., and Paredes, J. (2019). The Crosstalk between Cell Adhesion and Cancer Metabolism. Int. J. Mol. Sci. 20 (8). doi:10.3390/ijms20081933

Stincone, A., Prigione, A., Cramer, T., Wamelink, M. M. C., Campbell, K., Cheung, E., et al. (2015). The Return of Metabolism: Biochemistry and Physiology of the Pentose Phosphate Pathway. Biol. Rev. 90 (3), 927-963. doi:10.1111/brv.12140

Suganuma, K., Miwa, H., Imai, N., Shikami, M., Gotou, M., Goto, M., et al. (2010). Energy Metabolism of Leukemia Cells: Glycolysisversusoxidative Phosphorylation. Leuk. Lymphoma 51 (11), 2112-2119. doi:10.3109/10428194.2010.512966

Tabe, Y., Konopleva, M., and Andreeff, M. (2020). Fatty Acid Metabolism, Bone Marrow Adipocytes, and AML. Front. Oncol. 10, 155. doi:10.3389/ fonc. 2020.00155

Thompson, C., Sanders, J., Flournoy, N., Buckner, C., and Thomas, E. (1986). The Risks of central Nervous System Relapse and Leukoencephalopathy in Patients Receiving Marrow Transplants for Acute Leukemia. Blood 67 (1), 195-199. doi:10.1182/blood.v67.1.195.bloodjournal671195

Tucci, J., Chen, T., Margulis, K., Orgel, E., Paszkiewicz, R. L., Cohen, M. D., et al. (2021). Adipocytes Provide Fatty Acids to Acute Lymphoblastic Leukemia Cells. Front. Oncol. 11, 665763. doi:10.3389/fonc.2021.665763

Valastyan, S., and Weinberg, R. A. (2011). Tumor Metastasis: Molecular Insights and Evolving Paradigms. Cell 147 (2), 275-292. doi:10.1016/j.cell.2011.09.024 van der Velden, V. H. J., de Launaij, D., de Vries, J. F., de Haas, V., Sonneveld, E., Voerman, J. S. A., et al. (2016). New Cellular Markers at Diagnosis Are Associated with Isolated central Nervous System Relapse in Paediatric B-Cell Precursor Acute Lymphoblastic Leukaemia. Br. J. Haematol. 172 (5), 769-781. doi:10.1111/bjh.13887

van der Zwet, J. C. G., Buijs-Gladdines, J. G. C. A. M., Cordo', V., Debets, D. O., Smits, W. K., Chen, Z., et al. (2021). MAPK-ERK Is a central Pathway in T-Cell Acute Lymphoblastic Leukemia that Drives Steroid Resistance. Leukemia. doi:10.1038/s41375-021-01291-5

Vardiman, J. W., Thiele, J., Arber, D. A., Brunning, R. D., Borowitz, M. J., Porwit, A., et al. (2009). The 2008 Revision of the World Health Organization (WHO) Classification of Myeloid Neoplasms and Acute Leukemia: Rationale and Important Changes. Blood 114 (5), 937-951. doi:10.1182/blood-2009-03-209262

Wang, J., Liu, X., Qiu, Y., Shi, Y., Cai, J., Wang, B., et al. (2018). Cell AdhesionMediated Mitochondria Transfer Contributes to Mesenchymal Stem CellInduced Chemoresistance on T Cell Acute Lymphoblastic Leukemia Cells. J. Hematol. Oncol. 11 (1), 11. doi:10.1186/s13045-018-0554-z

Warburg, O. (1956). On Respiratory Impairment in Cancer Cells. Science 124 (3215), 269-270. doi:10.1126/science.124.3215.269

Warburg, O. (1956). On the Origin of Cancer Cells. Science 123 (3191), 309-314. doi:10.1126/science.123.3191.309
Warburg, O. (1925). The Metabolism of Carcinoma Cells. J. Cancer Res. 9, 148-163. doi:10.1158/jcr.1925.148

Ward, P. S., Patel, J., Wise, D. R., Abdel-Wahab, O., Bennett, B. D., Coller, H. A., et al. (2010). The Common Feature of Leukemia-Associated IDH1 and IDH2 Mutations Is a Neomorphic Enzyme Activity Converting Alpha-Ketoglutarate to 2hydroxyglutarate. Cancer cell 17 (3), 225-234. doi:10.1016/j.ccr.2010.01.020

Wei, Q., Qian, Y., Yu, J., and Wong, C. C. (2020). Metabolic Rewiring in the Promotion of Cancer Metastasis: Mechanisms and Therapeutic Implications. Oncogene 39 (39), 6139-6156. doi:10.1038/s41388-020-01432-7

Whiteley, A. E., Price, T. T., Cantelli, G., and Sipkins, D. A. (2021). Leukaemia: a Model Metastatic Disease. Nat. Rev. Cancer 21 (7), 461-475. doi:10.1038/ s41568-021-00355-z

Williams, M. T. S., Yousafzai, Y., Cox, C., Blair, A., Carmody, R., Sai, S., et al. (2014). Interleukin-15 Enhances Cellular Proliferation and Upregulates CNS Homing Molecules in Pre-B Acute Lymphoblastic Leukemia. Blood 123 (20), 3116-3127. doi:10.1182/blood-2013-05-499970

Williams, M. T. S., Yousafzai, Y. M., Elder, A., Rehe, K., Bomken, S., FrishmanLevy, L., et al. (2016). The Ability to Cross the Blood-Cerebrospinal Fluid Barrier Is a Generic Property of Acute Lymphoblastic Leukemia Blasts. Blood 127 (16), 1998-2006. doi:10.1182/blood-2015-08-665034

Windisch, R., Pirschtat, N., Kellner, C., Chen-Wichmann, L., Lausen, J., Humpe, A., et al. (2019). Oncogenic Deregulation of Cell Adhesion Molecules in Leukemia. Cancers (Basel) 11 (3). doi:10.3390/cancers11030311

Winter, S. S., Dunsmore, K. P., Devidas, M., Wood, B. L., Esiashvili, N., Chen, Z., et al. (2018). Improved Survival for Children and Young Adults with T-Lineage Acute Lymphoblastic Leukemia: Results from the Children's Oncology Group AALL0434 Methotrexate Randomization. Jco 36 (29), 2926-2934. doi:10.1200/jco.2018.77.7250

Wolpaw, A. J., and Dang, C. V. (2018). Exploiting Metabolic Vulnerabilities of Cancer with Precision and Accuracy. Trends Cel Biol. 28 (3), 201-212. doi:10.1016/j.tcb.2017.11.006

Xu, X., zur Hausen, A., Coy, J. F., and Löchelt, M. (2009). Transketolase-like Protein 1 (TKTL1) Is Required for Rapid Cell Growth and Full Viability of Human Tumor Cells. Int. J. Cancer 124 (6), 1330-1337. doi:10.1002/ijc.24078

Yao, H., Price, T. T., Cantelli, G., Ngo, B., Warner, M. J., Olivere, L., et al. (2018). Leukaemia Hijacks a Neural Mechanism to Invade the central Nervous System. Nature 560 (7716), 55-60. doi:10.1038/s41586-018-0342-5

Ye, H., Minhajuddin, M., Krug, A., Pei, S., Chou, C.-H., Culp-Hill, R., et al. (2021). The Hepatic Microenvironment Uniquely Protects Leukemia Cells through Induction of Growth and Survival Pathways Mediated by LIPG. Cancer Discov. 11 (2), 500-519. doi:10.1158/2159-8290.cd-20-0318

Yu, X., Zhang, H., Yuan, M., Zhang, P., Wang, Y., Zheng, M., et al. (2019). Identification and Characterization of a Murine Model of BCR-ABL1+ A-cute B-lymphoblastic L-eukemia with central N-ervous S-ystem M-etastasis. Oncol. Rep. 42 (2), 521-532. doi:10.3892/or.2019.7184

Zhang, C., Zhang, Z., Zhu, Y., and Qin, S. (2014). Glucose-6-phosphate Dehydrogenase: a Biomarker and Potential Therapeutic Target for Cancer. Acamc 14 (2), 280-289. doi:10.2174/18715206113136660337

Zhou, F., Wen, Y., Jin, R., and Chen, H. (2019). New Attempts for central Nervous Infiltration of Pediatric Acute Lymphoblastic Leukemia. Cancer Metastasis Rev. 38 (4), 657-671. doi:10.1007/s10555-019-09827-z

Conflict of Interest: The authors declare that the research was conducted in the absence of any commercial or financial relationships that could be construed as a potential conflict of interest.

Publisher's Note: All claims expressed in this article are solely those of the authors and do not necessarily represent those of their affiliated organizations, or those of the publisher, the editors and the reviewers. Any product that may be evaluated in this article, or claim that may be made by its manufacturer, is not guaranteed or endorsed by the publisher.

Copyright $\odot 2021$ Sharma, Keewan and Matlawska-Wasowska. This is an openaccess article distributed under the terms of the Creative Commons Attribution License (CC BY). The use, distribution or reproduction in other forums is permitted, provided the original author(s) and the copyright owner(s) are credited and that the original publication in this journal is cited, in accordance with accepted academic practice. No use, distribution or reproduction is permitted which does not comply with these terms. 